Academic Study

\title{
Q Factors Influencing the Application of a Biopsychosocial Perspective in Clinical Judgement of Chronic Pain: Interactive Management with Medical Students
}

\footnotetext{
Christopher P. Dwyer, PhD ${ }^{1,2}$, Phoebe E. McKenna-Plumley, BA ${ }^{1}$, Hannah Durand, MSc ${ }^{1,2}$, Emer M. Gormley, BSc ${ }^{1}$, Brian W. Slattery, PhD ${ }^{1,2}$, Owen M. Harney, BA², Pádraig MacNeela, PhD², and Brian E. McGuire, PhD ${ }^{1,2}$

From: ${ }^{1}$ Centre for Pain Research, National University of Ireland, Galway, Ireland; ${ }^{2}$ Schoo of Psychology, National University of Ireland, Galway, Ireland

Address Correspondence: Christopher P. Dwyer, PhD Centre for Pain Research, School of Psychology, National University of Ireland, Galway, Ireland E-mail: christopher. dwyer.phd@gmail.com

Disclaimer: This research was funded by the Health Research Board Interdisciplinary Capacity Enhancement Award (Ref: ICE/2011/19), received ethical approval from the NUIG Research Ethics Committee prior to implementation of the procedure, and was performed in agreement with the Declaration of Helsinki. . Conflict of interest: Each author certifies that he or she, or a member of his or her immediate family, has no commercial association (i.e., consultancies, stock ownership, equity interest, patent/licensing arrangements, etc.) that might pose a conflict of interest in connection with the submitted manuscript.

Manuscript received: 07-01-2016

Revised manuscript received: 02-07-2017 Accepted for publication: 03-08-2017

Free full manuscript: www. painphysicianjournal.com

Background: Though there is wide support for the application of biopsychosocial perspectives in clinical judgement of chronic pain cases, such perspectives are often overlooked due to either inadequate training or attitudes favoring a biomedical approach. Recent research has indicated that despite such explanations, both established general practitioners (GP) and medical students account for some psychosocial factors when making clinical judgements regarding chronic pain cases, but report not being likely to apply these in real-world, clinical settings due to numerous factors, including available time with patients. Thus, it is evident that a greater understanding of clinical judgement-making processes and the factors that affect application of these processes is required, particularly regarding chronic pain.

Objectives: The aims of the current study were to investigate medical students' conceptualizations of the factors that influence application of a biopsychosocial approach to clinical judgement-making in cases of chronic pain using interactive management (IM), model the relationships among these factors, and make recommendations to chronic pain treatment policy in light of the findings.

Study Design: The current study used IM to identify and model factors that influence the application of a biopsychosocial approach to clinical judgement-making in cases of chronic pain, based on medical students' conceptualizations of these factors.

Setting: Two university classrooms.

Methods: IM is a systems thinking and action mapping strategy used to aid groups in developing outcomes regarding complex issues, through integrating contributions from individuals with diverse views, backgrounds, and perspectives. IM commonly utilizes the nominal group technique and interpretive structural modeling, which in this context were employed to help medical students identify, clarify, and model influences on the application of biopsychosocial perspectives in treating chronic pain patients.

Results: Results of IM group work revealed 7 core biopsychosocial approach application categories: GP attitudes, cost, GP knowledge, time, patient-doctor relationship, biomedical factors. and patient perception. GP attitudes was the most critical driver of all other competencies in the system, with cost and GP knowledge revealed as secondary drivers.

Limitations: Potential differences in level of prior biopsychosocial perspective knowledge across participants and a potentially small sample size (though consistent with past research and appropriate for an exploratory study of this nature - for purposes of achieving the depth and richness of the deliberation and qualitative insights revealed by participants using the IM methodology).

Conclusions: Results from this study may be used to both recommend further research on the identified factors influencing application of biopsychosocial perspectives in treatment of chronic pain and support amendment to extant health care policy, particularly with respect to cost, GP attitudes, and knowledge. Though this research claims neither that the influences identified are the only influences on biopsychosocial application, nor the order of their importance, the research does contribute to an ongoing effort to better understand the factors that influence doctors in their treatment of chronic pain.

Key words: Chronic pain, biopsychosocial, medical education, clinical judgement, interactive management, pain management

Pain Physician 2017; 20:E951-E960
} 


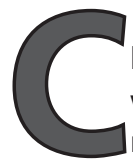

hronic pain (CP) is a major health care burden with wide-ranging effects; however, its management is often difficult, as there may be no pathophysiological cause in many cases (1). Traditional treatment methods prescribed according to the biomedical model (i.e., conceptualization of medical illness or disorder that includes biological factors and excludes psychological and/or social factors) often fail to adequately manage $\mathrm{CP}$ and may even contribute to further patient disability (2-4). A commonly cited alternative is treatment based on the biopsychosocial (BPS) model, which provides a better foundation for understanding CP (5) and addresses the importance of psychological and social interactions, as well as biological components in forming the individual's experience of their pain (6).

There is wide support for the BPS perspective in existing research, indicating that non-medical factors - psychological and social (e.g., pain catastrophizing, fear-avoidance beliefs, and concerns regarding work and family) - are critical in the perpetuation of CP (713). It is important to recognize that BPS risk factors do not exist in a vacuum, and should be considered within a broader context. Situational and socioeconomic factors such as older age, health care provision, emotional impact on the patient's family, and level of social integration are all interconnected with these psychosocial risk factors $(14,15)$.

However, reports reveal that physicians' adherence to guidelines for physical and psychosocial assessment is low (16). There is also a lack of knowledge and skills among physicians in identifying and tackling psychosocial risk factors $(17,18)$. Little teaching time is generally dedicated to pain management in health care training (19), including education of physicians (20). Lack of knowledge about psychosocial risk factors and low adherence to clinical guidelines suggests that doctors may miss important cues which may improve how pain is managed (21). Consistent with this standpoint, from a patient perspective, medical care is often described in mixed terms, with patients sometimes feeling misunderstood and unsupported by general practitioners (GPs), as they attempt to negotiate a life-changing experience characterized by distress and loss (22).

Recent research has reasoned that medical students are more likely to adopt a BPS approach as part of their clinical decision-making, as they are more likely to have received some BPS education and, therefore, are potentially more open to psychosocial influences in the treatment of $\mathrm{CP}$ (23). However, despite openness to the perspective or receipt of relevant training, medical students report not being likely to apply the BPS model in clinical settings due to extraneous factors, particularly, available time with patients (24). Though existing literature indicates beneficial effects of treatment utilizing a BPS perspective for CP patients (7-13), there are a number of barriers to the application of this approach in clinical judgement settings. As a result, greater insight into both the judgement processes and the factors that affect application of these processes is required. The current research employed interactive management (25) to develop a model of influences on clinical judgement-making regarding $\mathrm{CP}$ according to a BPS perspective. The depth of deliberation and qualitative insights revealed using the interactive management methodology can make a valuable contribution in better understanding the nature of CP treatment and will provide a greater understanding of the obstacles to applying the BPS model in clinical settings.

\section{Method}

\section{Participants}

Fourteen third - fifth year medical students (Group 1: 3 men and 4 women; Group 2: 5 men and 2 women) aged 20 - 23 years, from the National University of Ireland, Galway, participated in the current research. At the time of participation, all students had completed both the relevant BPS aspect of their education and some clinical work placement. In return for their voluntary participation, students were provided with refreshments and each awarded a $€ 20$ voucher.

\section{Materials and Measures}

Interactive management (IM) is a systems thinking and action mapping strategy, drawing from behavioral and cognitive sciences $(25,26)$, used to aid groups in integrating contributions from individuals with diverse views, backgrounds, and perspectives in dealing with complex issues (27-35). The IM approach carefully delineates content and process roles, by (i) assigning responsibility for contribution of ideas to the participants and (ii) assigning responsibility to the facilitator for choosing and implementing selected methodologies for idea generation, clarification, structuring, interpretation, and idea amendment. As IM involves mapping of arguments generated by a group of knowledgeable individuals, it was considered an appropriate methodology to catalyze collec- 
tive intelligence and critical thought in the process of generating a model (36) of influences on application of a BPS perspective. IM utilizes a set of methodologies, matched to the phase of group interaction and the requirements of the situation - the current study used both the nominal group technique (NGT) and interpretive structural modeling (ISM) to help medical students identify, clarify, and model influences on BPSPA $\{$ sp $\}$ in treating CP patients. NGT (37) is a method that allows individual ideas to be collated in 5 steps: [1] presentation of a stimulus question; [2] silent generation of ideas in writing by each participant working alone; [3] presentation of ideas by participants, recorded on paper by the facilitator, and posted on walls surrounding the group; [4] serial discussion of the posted ideas for the purpose of clarifying their meaning; and [5] implementation of a closed voting process in which each participant is asked to select and rank what they perceive as the 5 most important ideas, with the results compiled and displayed for review by the group. Specifically, in the current case study, participants initially worked to identify influences on BPS-PA, based on their relevant experiences; and by generating ideas in response to the question: "What are the most important factors that influence the application of a biopsychosocial perspective when making clinical judgements in treating chronic pain patients?"

ISM (38) is a computer-assisted methodology that helps a group to identify relationships among ideas and to impose structure on those ideas to help manage the complexity of the issue. The 5 steps of ISM are [1] identification and clarification of a list of ideas (e.g., using NGT); [2] identification and clarification of a "relational question" for exploring relationships among ideas (e.g., "Does idea A influence idea B?"); [3] development of a structural map by using the relational question to explore connections between pairs of ideas; [4] display and discussion of the map by the group; and [5] amendment to the map by the group, if needed. In the current case study, interdependencies among BPS application influences were examined, specifically, by asking: "Does $X$ significantly influence $Y$ ?" (e.g., Does physician attitude influence patient perception?) Using the ISM methodology, the groups engaged in discussion about each relational question and a vote was taken to determine the group's judgement about the relationship. A "yes" vote was entered into the ISM software by the IM facilitator if a majority of participants judged that there was a significant relationship between the pair of ideas; otherwise, a "no" vote was entered.

\section{Procedure}

Medical students were invited to participate in an IM session and presented with information regarding the nature of the study. Students were provided a choice of 2 different days to participate; thus, 2 IM sessions were conducted. Participants were brought together in classrooms where they were asked: "What are the most important factors that influence the application of a biopsychosocial perspective when making clinical judgements in treating chronic pain patients?" Prior to idea generation or discussion, the BPS perspective (i.e., the importance of psychological and social interactions, as well as biological components, in forming the individual's experience of their pain) was described to ensure clarity. All medical students were familiar with the perspective and then completed the idea generation phase of the study, with both groups initially generating a list of 19 influences on BPS-PA (see Table 1 for a list of ideas generated).

In order to facilitate open discussion, seating was arranged so that participants could clearly see and engage with each other. Consistent with NGT (37), within each group, participants identified what they considered as the most important influences in applying a BPS model. The facilitator sought elaboration or clarification when required and then invited the opinions of the group members. If an idea had already been presented, or if there was significant overlap in conceptualization (without distinction) between ideas, the person would present their next most important influence and so on, until everyone has had an opportunity to present a couple of ideas (depending on sample size of the group) or until an adequate number of pool of ideas (from which to identify and rank important ideas) has been reached. Each participant would have the same number of opportunities to present ideas. Each idea was then written on a poster on the wall. Subsequently, participants individually voted to select what they deemed the 5 most influences on application of a BPS perspective from the list generated by the group. The 8 highest ranked influences were compiled, displayed for review by the group, and were entered into the IM software by a trained IM facilitator.

Using the IM software, participants were then presented a series of questions describing relations among the 8 influences; for example, "Does $X$ significantly influence $Y$ ?" Once the discussion had come to a close, a vote regarding the relationship was taken and was entered into the software. In the 2 groups, a series of over 18 and 19 decisions, respectively, were needed to complete the matrix structuring work. 
Pain Physician: September/October 2017: 20:E951-E960

Table 1. Master list of influences generated by medical students and votes supporting each influence.

\begin{tabular}{|c|c|c|}
\hline \# Votes & Influence & Description \\
\hline \multicolumn{3}{|l|}{ Group 1: } \\
\hline 7 & $\begin{array}{l}\text { Evidence for effectiveness } \\
\text { on health outcomes }\end{array}$ & $\begin{array}{l}\text { Evidence of improved health outcomes when BPS issues are addressed (e.g., improved quality of life, } \\
\text { pain tolerance and pain relief). }\end{array}$ \\
\hline 5 & Time & $\begin{array}{l}\text { Amount of time available for consultation. Many patients and a limited time for consultation; more } \\
\text { time necessary per consultation to apply a BPS perspective. }\end{array}$ \\
\hline 5 & Willingness of doctors & $\begin{array}{l}\text { Level of willingness of doctors to apply the BPS perspective with respect to their abilities and } \\
\text { attitudes. }\end{array}$ \\
\hline 4 & Responsibility & $\begin{array}{l}\text { Identification of who is responsible for ensuring that all the patient's needs are fulfilled with respect } \\
\text { to BPS perspective (e.g., living conditions, psychological well-being and family stressors); and degree } \\
\text { of responsibility. }\end{array}$ \\
\hline 4 & $\begin{array}{l}\text { Cost to the individual } \\
\text { patient }\end{array}$ & Amount of cost to the individual with respect to medication, GP visits, travel, etc. \\
\hline $2(5)$ & Cost to the system & Amount of cost to the system; for example, potential budget confusion and budget allocation issues. \\
\hline $2(3)$ & $\begin{array}{l}\text { Practice of BPS judgment } \\
\text { skills }\end{array}$ & $\begin{array}{l}\text { The development of a systematic way of applying the perspective and subsequent level of practice in } \\
\text { dealing with BPS issues. }\end{array}$ \\
\hline $2(3)$ & Cost-effectiveness & $\begin{array}{l}\text { Potentially decreased costs for patients and the system; more cost effective than biomedical } \\
\text { treatments (e.g., medication); less required health service interactions. }\end{array}$ \\
\hline 2 & Education & Knowledge of practicing GPs to apply BPS perspective; more education potentially required. \\
\hline 1 & Decrease in drugs & Desire to decrease dependency on medication prescription and usage. \\
\hline 1 & Snowball effect & $\begin{array}{l}\text { If patient starts feeling better, they will be happier, sleep better and see other improvement, which in } \\
\text { turn will facilitate other improvements and provide the patient and their healthcare practitioner(s) } \\
\text { with a better understanding of their condition. }\end{array}$ \\
\hline 0 & No guarantee & $\begin{array}{l}\text { There is no guarantee that a BPS approach will exhibit improvements above and beyond biomedical } \\
\text { treatments. }\end{array}$ \\
\hline 0 & Patient perception & $\begin{array}{l}\text { A patient may be sceptical of the approach or not open-minded to it; discussion of psychosocial } \\
\text { factors with their GP may decrease patient self-efficacy. }\end{array}$ \\
\hline 0 & Side-effects of drugs & $\begin{array}{l}\text { In case-by-case situations, the prescription of some medications in previous consultations may affect } \\
\text { the patient's psychological and sociological perceptions. }\end{array}$ \\
\hline 0 & Support & External supports in place for the individual. \\
\hline 0 & Identification of associations & $\begin{array}{l}\text { Application of the perspective may allow for both the identification of other, previously unknown, } \\
\text { patient maladies and the associations among such maladies, chronic pain and other BPS aspects of } \\
\text { treatment. }\end{array}$ \\
\hline 0 & Treatment preference & $\begin{array}{l}\text { The BPS perspective provides for a less invasive treatment and potentially decreases other } \\
\text { complications and side-effects. }\end{array}$ \\
\hline 0 & Necessity & $\begin{array}{l}\text { The perspective assumes a combination of treatments, which may lead to additional stressors (e.g., } \\
\text { increased healthcare visits). }\end{array}$ \\
\hline 0 & Patient-centred nature & The perspective is more appropriate and desirable as it is patient-centred. \\
\hline \multicolumn{3}{|l|}{ Group 2: } \\
\hline 7 & Cost efficiency & Cost efficiency with respect to cost of treatment and to patient. \\
\hline 5 & Patient-doctor relationship & Patient-doctor relationship with respect to rapport, trust and compliance. \\
\hline 5 & Type of pain & Source and type of pain; e.g., non-pathophysiological. \\
\hline 5 & Patient perception & $\begin{array}{l}\text { Patient's: motivation to be well again and associated optimism of treatment; psychological well- } \\
\text { being; ability to cope with pain; outlook; and beliefs. }\end{array}$ \\
\hline 3 & Social support & $\begin{array}{l}\text { Existence of social support (e.g., family and friends); No social support or outlet may exacerbate } \\
\text { chronic pain. }\end{array}$ \\
\hline 2 & Comorbidity & Existence of comorbid and concurrent illnesses. \\
\hline 2 & Time & Time restrictions of doctors and patients; time efficiency. \\
\hline 2 & Patient knowledge & $\begin{array}{l}\text { Level of patient education and knowledge of illness; may allow for better preparedness; lack of } \\
\text { knowledge could lead to confusion/stress/influence perception of pain. }\end{array}$ \\
\hline 2 & Prognosis & A bad prognosis will influence future risk of disability and negatively affect a patient's perception. \\
\hline
\end{tabular}


Factors Influencing Application of a Biopsychosocial Perspective Regarding Chronic Pain

Table 1 (cont.). Master list of influences generated by medical students and votes supporting each influence.

\begin{tabular}{|c|c|l||}
\hline \# Votes & Influence & \multicolumn{1}{c|}{ Description } \\
\hline 1 & $\begin{array}{c}\text { Doctor's scepticism of } \\
\text { patient's pain }\end{array}$ & Doctor's scepticism of patient's pain (e.g., desire to obtain drugs or Munchausen syndrome). \\
\hline 1 & GP experience & GP's experience treating chronic pain. \\
\hline 0 & Subjectivity & Experience of chronic pain is subjective (i.e., different for each person). \\
\hline 0 & Patient stress & Stress of patient due to pain will influence how aggressive it is treated. \\
\hline 0 & Maladaptive behaviors & For example, patient's dependency on alcoholism, drugs, etc. \\
\hline 0 & Anxious caregivers & Disposition of caregivers and their influence on patients. \\
\hline 0 & Societal impact & Influence of society on: GP decision-making and pain treatment; patient behaviors (e.g., big boys don't cry). \\
\hline 0 & Access to services & Ease of access to health services, be they for medication, treatment engagement, etc. \\
\hline 0 & Pain threshold & Low versus high pain threshold of patients (e.g., "warrior" mentality). \\
\hline 0 & $\begin{array}{c}\text { Patient perception of } \\
\text { palliative care }\end{array}$ & Patient perception that because nothing else can be done, this is "the end." \\
\hline \hline
\end{tabular}

On completion of this discussion and voting session, a structural map describing relations among factors influencing the application of a BPS perspective was generated by the IM software and projected on a screen in front of the group. Participants then engaged in higher-order discussions regarding the structural map generated, after which the session closed and participants were thanked for their contributions. The duration of each of session was approximately 2 hours. Given that there were 2 (or more) groups that participated, a separate thematic analysis session, including 4 members of the research team (CPD, EMG, PEMP, and BWS), was required to collate the ideas generated across groups and subsume ideas into categories based on their commonality.

\section{Results}

Two structural maps were generated based on the deliberation and voting that took place during the structuring sessions (see Figs. 1 and 2). The structural maps generated by the groups are to be read from left to right, with arrows indicating significantly influences. For example, in the first map (Fig. 1), reading the structure from left to right, one factor influencing the application of a BPS perspective (i.e., in this context, cost effectiveness) can be seen to significantly influence a total of 7 additional factors. For example, the presence of more than one element in a box signifies a cyclic relationship, whereby each factor influences, and is being influenced by, each of the other factors.

Results are divided into 3 sections. Section 1 describes the 2 structural maps generated during the IM sessions. Section 2 presents a category analysis of the BPS-PA factors generated by participants. Section 3 presents a meta-analysis of the top ranked ideas from the 2 sessions and an overall influence model.

\section{I: Structural Models Generated}

With respect to Group 1, though the factor referred to as evidence for effectiveness on health outcomes received the most votes with respect to importance, the factor referred to as cost-effectiveness (i.e., potentially decreased costs for patients and the system; more cost effective than biomedical treatments [e.g., medication]; fewer required health service interactions) emerged as the most fundamental driver of other factors - particularly, responsibility, evidence for effectiveness, time, practice, and cost to the system (i.e., based on the ISM relationship voting). This set of factors influenced willingness of doctors, which in turn, influenced cost to the individual patient.

In Group 2, the factor referred to as cost efficiency (i.e., cost of treatment and cost to the patient) received the most votes with respect to importance. The factors referred to as patient-doctor relationship, type of pain, patient perception, social support, comorbidity, time, and patient knowledge emerged as the fundamental drivers of other BPS-PA factors - particularly, cost efficiency and prognosis.

\section{II: Category Analysis of the BPS-PA Factors Generated by Medical Students}

The 2 sessions generated a total of 38 factors -22 of which received at least one vote during the IM process. The subsequent thematic analysis session, including 4 members of the research team (CPD, EMG, PEMP, and BWS), generated a total of 7 categories based on the commonality among factors (see Table 2). 


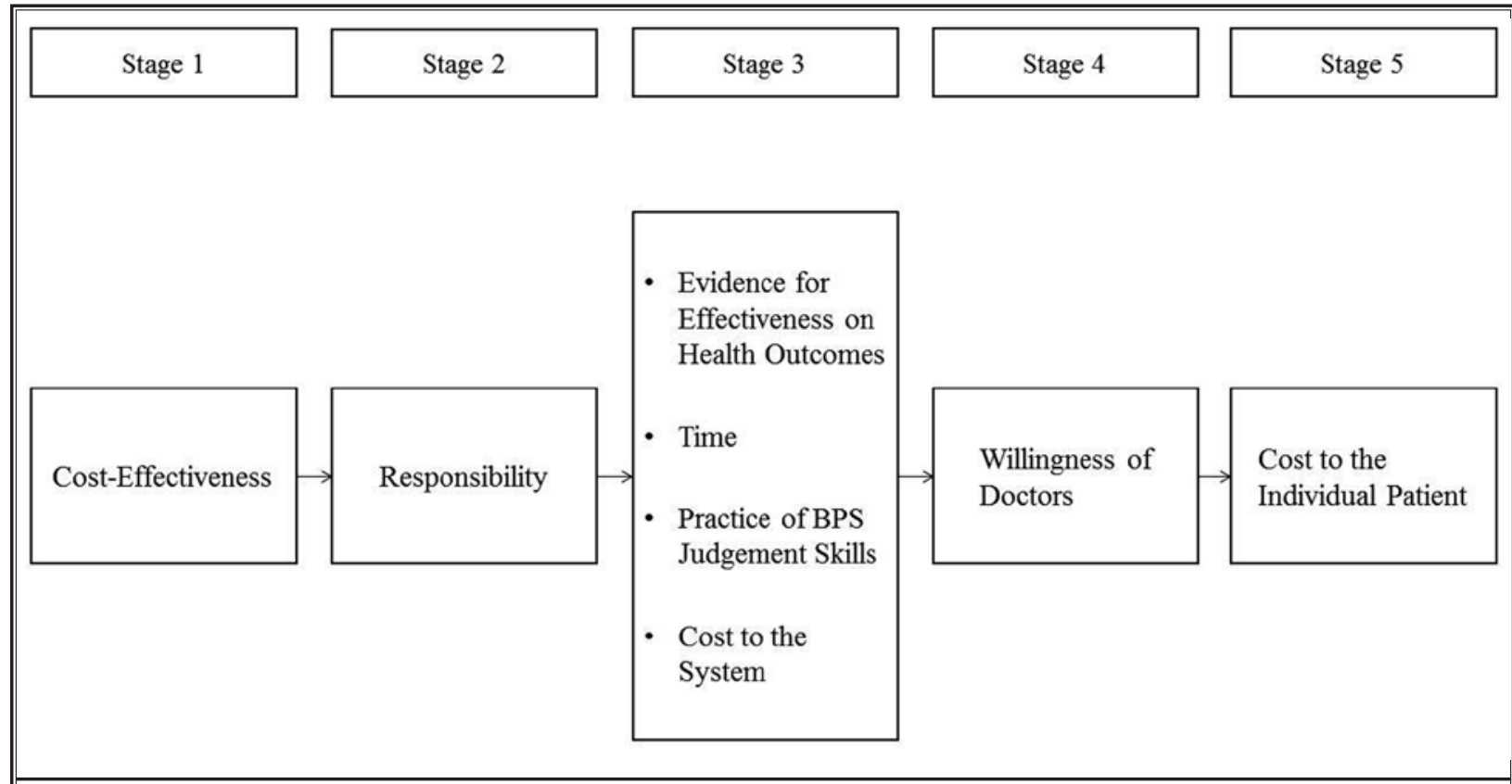

Fig. 1. Structural map of Group 1's influences on the application of a biopsychosocial perspective in the treatment of chronic pain.

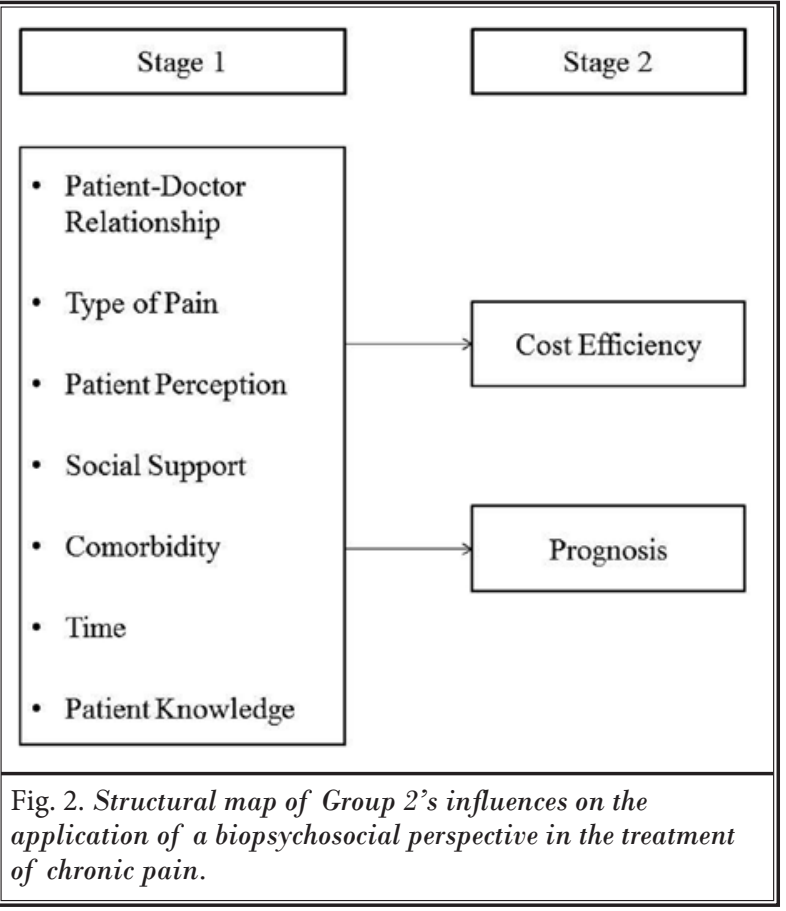

\section{III: Meta-analysis: Influence Model of BPS-PA Factors}

A total of 17 factors from across the 7 categories appeared in the maps generated by the 2 groups. A struc- tural meta-analysis of the maps was conducted to develop a higher-order influence model of categories. In order to conduct these meta-analyses, the following scores were computed to estimate the influence of each category:

\section{Position Score}

Each structural map places ideas in stages $(39,40)$. Ideas to the far right are assigned the lowest position score (i.e., 1). Each position move to the left garners an additional point, with those in the leftmost stage assigned the highest score (i.e., depending on the number of levels in the structure).

\section{Antecedent and Succeeding Score}

The antecedent score is the number of factors lying to the left of a particular idea, in which the former will influence the latter. The succeeding score is the number of factors lying to the right of an idea, which are influenced by the former.

\section{Net Succeeding/Antecedent Score}

The net succeeding/antecedent (Net SA) score is the succeeding score minus the antecedent score. If the Net SA score is positive, it means that the function is a net source of influence. If the Net SA score is negative, it means that the function is a net receiver of influence $(39,40)$. 


\section{Influence Score}

The influence score is the sum of the position score and the net SA score.

Influence scores were calculated for each of the factors appearing in the structural maps. Total category influence scores were then calculated by summing the influence scores. Average category influence scores were then calculated by dividing the total category influence score by the number of factors (initially mapped) in the category. A structural influence model was developed using average category influence scores. The resulting model is presented in Fig. 3. Results from the meta-analyses revealed that GP attitudes was identified as having the strongest influence on whether the BPS perspective would be applied in judgementmaking regarding $\mathrm{CP}$ cases (and to a lesser extent, cost, GP knowledge, and thereafter, time); whereas, patient perception was seen as highly influenced by other categories.

\section{Discussion}

The current study used IM to identify, clarify, rank, categorize, and structure relationships among factors influencing application of a BPS perspective, as described by medical students in the context of clinical decision-making regarding future risk of CP. Participants identified and structured a range of factors, which were categorized as cost, time, GP knowledge, GP attitudes, the patient-doctor relationship, biomedical factors, and patient perception. Overall, it was found that the critical drivers of whether a BPS perspective would be applied were cost, GP knowledge, and GP attitudes; whereas, the factor most influenced by other factors was patient perception. Interestingly, these 4 categories were also those with the highest percentage of initial votes.

GP attitudes was the most critical driver identified, which referred to willingness of a doctor to apply a BPS perspective and ensure that all the patient's BPS needs are fulfilled. In short, it was considered that GP attitudes, above and beyond all other factors, would dictate whether a BPS perspective would be applied. Cost was a secondary driver identified, which referred to cost of BPS treatment in comparison with biomedical treatment (e.g., medication) and amount of health service interactions necessary to treat, with respect to both system (e.g., budgetary allocation) and patient (e.g., cost of medication, GP visits, travel, etc.). GP knowledge was another secondary driver identified, referring to development of knowledge, through ex-
Table 2. BPS application categories derived from the thematic analysis session.

\begin{tabular}{|c|c|}
\hline Category & Influences \\
\hline \multirow{4}{*}{ Cost } & Cost to the Individual Patient \\
\hline & Cost to the System \\
\hline & Cost-Effectiveness \\
\hline & Cost efficiency \\
\hline \multirow{2}{*}{ Time } & Time (Group 1) \\
\hline & Time (Group 2) \\
\hline \multirow{4}{*}{ GP Knowledge } & $\begin{array}{l}\text { Evidence for effectiveness on health } \\
\text { outcomes }\end{array}$ \\
\hline & Practice of BPS Judgment Skills \\
\hline & Education \\
\hline & GP Experience \\
\hline \multirow{3}{*}{ GP Attitudes } & Willingness of doctors \\
\hline & Responsibility \\
\hline & Decrease in drugs \\
\hline \multirow{3}{*}{ Patient-Doctor Relationship } & Patient-Doctor Relationship \\
\hline & Doctor's scepticism of patient's pain \\
\hline & Social support \\
\hline \multirow{2}{*}{ Biomedical Factors } & Type of pain \\
\hline & Comorbidity \\
\hline \multirow{4}{*}{ Patient Perception } & Patient perception \\
\hline & Patient Knowledge \\
\hline & Prognosis \\
\hline & Snowball Effect \\
\hline
\end{tabular}

perience, practice, and or consideration of evidence for improved health outcomes in treating CP through a BPS perspective. However, based on influence modeling, patient perception (i.e., the patient's motivation to be well again, associated optimism regarding treatment, psychological well-being, ability to cope with pain, outlook, beliefs, education, and knowledge of illness; as well as subsequent effects of these perceptions on future pain management) was the least influential factor. However, this does not diminish its importance, given that it is, as a result, potentially the most influenced by other factors.

The remaining factors included in the overall model were the patient-doctor relationship, biomedical factors, and time, which spanned from Stages $3-4$ with respect to influence. The patient-doctor relationship referred to rapport and trust shared between a patient and their doctor; including subsequent patient adherence to prescribed treatment, the doctor's consideration of external supports available to the patient, and the 


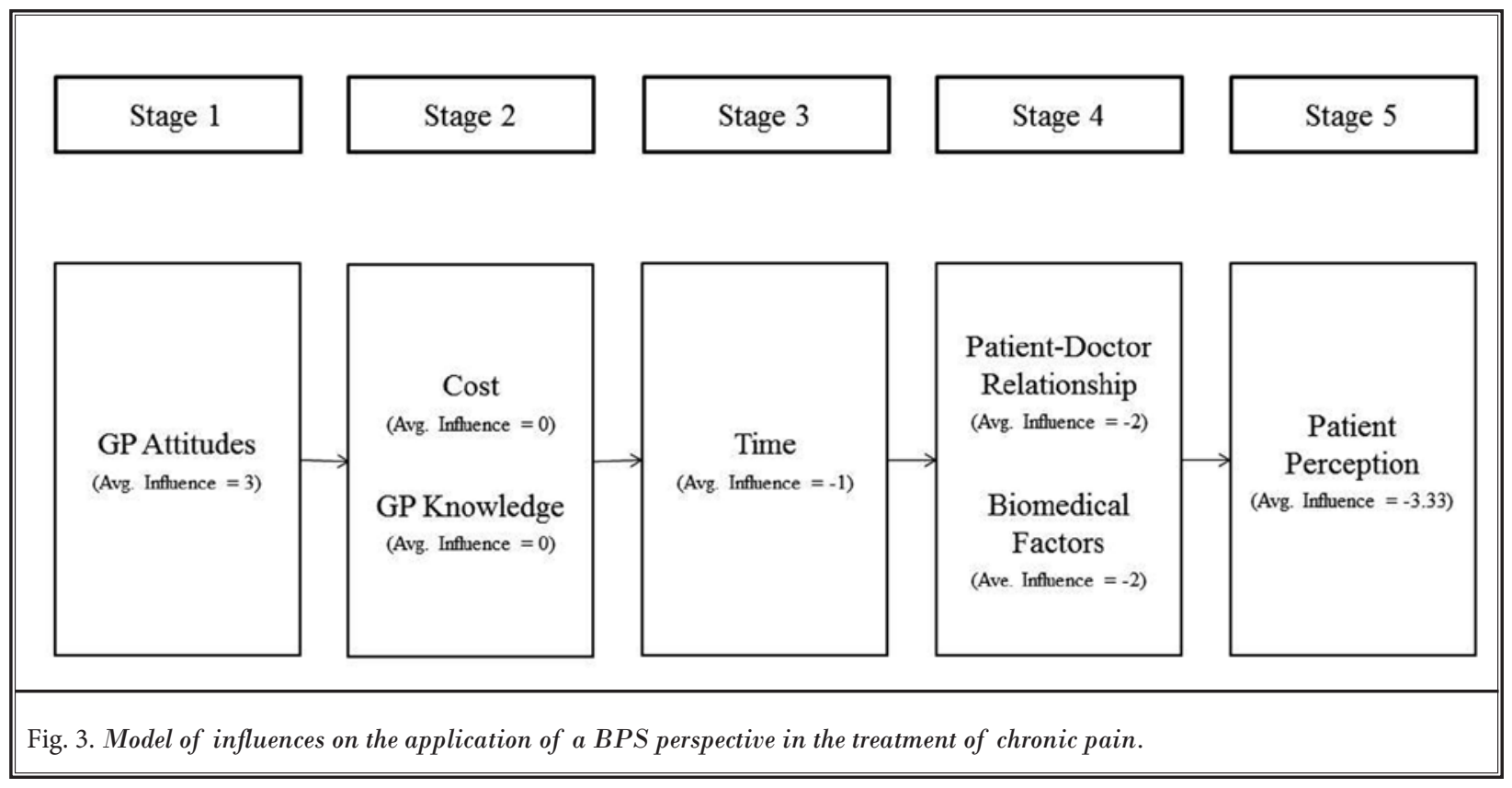

doctor's perception (e.g., scepticism or acceptance) of their patient's pain. Biomedical factors referred to the source and type of pain (e.g., non-pathophysiological) as well as the existence of comorbid conditions and/or concurrent illnesses. Time referred to consideration of the limited time of both doctors (e.g., time available for consultation) and patients (e.g., time spent traveling and waiting), with respect to how efficiently the BPS perspective can be applied within the available time (i.e., application may require more time). Notably, time was identified in previous research as the primary reason why students reported not being likely to apply these psychosocial factors in real-world, clinical settings (24). Though it is surprising that time was not revealed as a more critical driver in the current research, it also suggests that GP attitudes, cost, and GP knowledge may be more subtle influences that may not have been elucidated without the IM process.

Though this research has yielded some interesting findings, potential limitations and implications for future research require consideration. While it can be argued that one limitation was a small sample, it was appropriate for an exploratory study of this nature (39). Furthermore, the depth of deliberation and qualitative insights revealed through the IM methodology contribute to a better understanding of the application of BPS perspectives in clinical settings, particularly with respect to $\mathrm{CP}$ treatment. Another potential limitation is that it can be argued that there may be subtle differences in level of practice or application across the Year 3 - 5 medical students; however, all students had received formal instruction in BPS perspectives prior to participation, as part of their medical education.

The current study does not argue that the 7 categories identified are the only influences on the application of the BPS model, nor does it outline the order of their importance. However, it does provide a foundation for future research to investigate potential means of overcoming barriers, identified in the current study, to applying the BPS model. To address these issues, for example, a mobile app is currently in development that will aid GPs in assessing future risk of chronic lower back pain-related disability. The app requires GPs to input a variety of BPS symptom-associated cues (e.g., problems with sleep, mobility, motivation, and social activity) and subsequently, the app will compute the patient's future risk of chronic lower back pain-related disability. Future research should also evaluate the usability, design, and efficacy of such an app among health care practitioners. Given that research highlights the importance of BPS-PA in clinical settings (7-13), future research should also investigate other potential means of overcoming barriers to applying the BPS model in the treatment of chronic pain, particularly from the perspective of informing existing practices in clinical judgment-making regarding $\mathrm{CP}$ cases. 
Conclusion

In conclusion, the current research examined medical students' conceptualizations of factors that influence the application of a BPS approach to clinical judgement-making in cases of CP. Results may be used to both recommend further research on the factors identified as influencing application of the BPS model in treatment of $\mathrm{CP}$ and suggest several influences in decision-making regarding $\mathrm{CP}$ cases, particularly with respect to cost, GP attitudes, and knowledge. This research is a contribution to an on-going effort to better understand the nature of CP treatment and the understanding obtained through this study may assist medical educators who wish to further understand how student physicians conceptualize and reflect on their application of a BPS perspective in their own treatment of CP patients.

\section{References}

1. Pillastrini P, Bonfiglioli R, Banchelli F, Capra F, Resende FL, Villafane JH, Vanti C, Violante FS. The effect of a multimodal group programme in hospital workers with persistent low back pain: A prospective observational study. Med Lav 2013; 104:380-392.

2. Pincus $T$, Kent $P$, Bronfort $G$, Loisel $P$, Pransky G, Hartvigsen J. Twenty-five years with the biopsychosocial model of low back pain-is it time to celebrate? A report from the twelfth international forum for primary care research on low back pain. Spine 2013; 38:2118-2123.

3. Nicholas MK, Linton SJ, Watson PJ, Main C). Early identification and management of psychological risk factors ("yellow flags") in patients with low back pain: A reappraisal. Phys Ther 2011; 91:737-753.

4. O'Sullivan P. It's time for change with the management of non-specific chronic low back pain. Br J Sports Med 2012; 46:224-227.

5. Main CJ, Williams AC. ABC of psychological medicine: Musculoskeletal pain. BM] 2002; 325:534-537.

6. Kennedy N, Healy J, O'Sullivan K. The beliefs of third-level healthcare students towards low-back pain. Pain Research and Treatment 2014; 2014. \{need pages\}

7. Shaw WS, Campbell P, Nelson CC, Main C), Linton SJ. Effects of workplace, family and cultural influences on low back pain: What opportunities exist to address social factors in general consultations? Best Pract Res Clin Rheumatol 2013; 27:637-648.

8. Pincus T, Vogel S, Burton AK, Santos R, Field AP. Fear avoidance and prognosis in back pain: A systematic review and synthesis of current evidence. Arthritis Rheum 2006; 54:3999-4010.

9. Shaw WS, Van der Windt DA, Main C), Loisel P, Linton SJ. Early patient screen- ing and intervention to address individual-level occupational factors ("blue flags") in back disability. J Occup Rehabil 2009; 19:64-80.

10. Crombez G, Eccleston C, Van Damme S, Vlaeyen JWS, Karoly P. Fear-avoidance model of chronic pain: The next generation. Clin J Pain 2012; 28:475-483.

11. Linton SJ, Shaw WS. Impact of psychological factors in the experience of pain. Phys Ther 2011; 91:700-711.

12. Gatchel RJ, Peng YB, Peters ML, Fuchs PN, Turk DC. The biopsychosocial approach to chronic pain: Scientific advances and future directions. Psychol Bull 2007; 133:581-624.

13. Balagué F, Mannion AF, Pellisé F, Cedraschi C. Non-specific low back pain. The Lancet 2012; 379:482-491.

14. Steenstra I, de Bruin L, Mahood Q, Irvin E, Hogg-Johnson S, Heijmans $M$, Verbeek J. Prognostic factors for duration of sick leave in patients sick listed with acute low back pain: An update of a systematic review of the literature. Occup Env Med 2011; 68:A74-A75.

15. Main CJ, George SZ. Psychologically informed practice for management of low back pain: Future directions in practice and research. Phys Ther 2011; 91:820-824.

16. Van Tulder $M$, Becker A, Bekkering $T$, Breen A, Gil del Real MT, Hutchinson A, Koes B, Laerum E, Malmivaara A. European guidelines for the management of acute nonspecific low back pain in primary care. Eur Spine ] 2006; 15:s169-s191.

17. Overmeer T, Boersma K, Denison E, Linton SJ. Does teaching physical therapists to deliver a biopsychosocial treatment program result in better patient outcomes? A randomized controlled trial. Phys Ther 2011; 91:804-819.

18. Pincus T, Burton AK, Vogel S, Field AP. A systematic review of psychological fac- tors as predictors of chronicity/disability in prospective cohorts of low back pain. Spine 2002; 27:E109-E120.

19. Fullen B, Hurley DA, Power C, Canavan D, O'Keeffe D. The need for a national strategy for chronic pain management in Ireland. Ir J Med Sci 2006; 175:68-73.

20. Green CR, Wheeler JRC, LaPorte F, Marchant B, Guerrero E. How well is chronic pain managed? Who does it well? Pain Medicine 2002; 3:56-65.

21. van Tulder MW, Tuut $M$, Pennick $V$, Bombardier C, Assendelft WJJ. Quality of primary care guidelines for acute low back pain. Spine 2004; 29:E357-E362.

22. Coole C, Watson PJ, Drummond A. Staying at work with back pain: Patients' experiences of work-related help received from GPs and other clinicians. A qualitative study. BMC Musculoskelet Disord 2010; 11:190.

23. McNair A, Moran C, McGrath E, Naqvi S, Connolly C, McKenna V, Kropmans T. How we implemented an integrated professionalism curriculum to 2 nd year medical students at the National University of Ireland Galway Medical School, with examples from students' final output. Med Teach 2011; 33:710-712.

24. Dwyer CP, MacNeela $P$, Durand $H$, O'Connor LL, Main CJ, McKenna-Plumley PE, Hamm RM, Reynolds B, Conneely S, Slattery BW, Taheny D, NicGabhainn S, Murphy AW, Kropmans T, McGuire BE. Effects of biopsychosocial education on the clinical judgments of medical students and GP trainees regarding future risk of disability in chronic lower back pain: A randomized control trial. J Pain under review. \{AU: Update reference\}

25. Warfield JN, Cárdenas AR. A Handbook of Interactive Management. 2nd edition. lowa State University Press, Ames, IA, 1994 . 
26. Hogan MJ, Dwyer CP, Harney OM, Noone C, Conway RJ. Metacognitive skill development and applied systems science: A framework of metacognitive skills, self-regulatory functions and realworld applications. In: Metacognition: Fundaments, Applications, and Trends. Springer, Berlin, 2015. \{Who are the editors or authors of the book?

27. Ackoff RL. Creating the Corporate Future: Plan or Be Planned for. John Wiley and Sons, New York, 1981.

28. Argyris C. Reasoning, Learning, and Action: Individual and Organizational. Jossey-Bass San Francisco, CA, 1982.

29. Cleveland $\mathrm{H}$. The decision makers. Center Magazine 1973; 6:9-18.

30. Deal TE, Kennedy AA. Corporate Cultures: The Rites and Rituals of Corporate Life. Addison-Wesley, Reading, MA, 2000.

31. Dwyer CP, Harney OM, Hogan MJ. Us- ing interactive management to define and cultivate critical thinking competencies. Educ Technol Res Dev 2014; 62:687-709.

32. Kemeny JC. Saving American democracy: The lessons of Three Mile Island. Tech Rev 1980; 83:64-75.

33. Rittel HWJ, Webber MM. Dilemmas in a general theory of planning. Policy Sci 1973; 4:155-169.

34. Sato T. Determination of hierarchical networks of instructional units using the ISM method. Educ Technol Res 1979; 3:67-75.

35. Simon HA. The New Science of Management Decision. Harper \& Row, New York, NY, 1960.

36. Dwyer CP, Hogan MJ, Harney OM, Kavanagh $C$. Facilitating a student-educator conceptual model of dispositions towards critical thinking through interac- tive management. Educ Technol Res Dev 2016. \{need volume and pages\}

37. Delbecq AL, Van de Ven AH, Gustafson DH. Group Techniques for Program Planning: A Guide to Nominal Group and Delphi Processes. Scott, Foresman, Glenview, IL, 1975.

38. Warfield JN. Science of Generic Design: Managing Complexity through Systems Design. and edition. Intersystems, Salinas, CA, 1994.

39. Broome BJ, Fulbright L. A multistage influence model of barriers to group problem solving a participant-generated agenda for small group research. Small Group Res 1995; 26:25-55.

40. Broome BJ. Collective design of the future: Structural analysis of tribal vision statements. Am Indian Q 1995; 19:205-227. 